\title{
One Bat's Waste is Another Man's Treasure: A DNA Metabarcoding Approach for the Assessment of Biodiversity and Ecosystem Services Using Bat Faeces
}

Thomas Curran ( $\nabla$ thomascurran303@gmail.com )

Waterford Institute of Technology https://orcid.org/0000-0001-5184-4498

Samuel Browett

Waterford Institute of Technology

David O'Neill

Waterford Institute of Technology

Aidan O'Hanlon

National Museum of Ireland

Catherine O'Reilly

Waterford Institute of Technology

Andrew Harrington

Waterford Institute of Technology

Allan McDevitt

University of Salford

Denise O'Meara

Waterford Institute of Technology

Research Article

Keywords: Arthropod diversity, Dietary analysis, Non-invasive genetics, Rhinolophus hipposideros

Posted Date: January 7th, 2022

DOI: https://doi.org/10.21203/rs.3.rs-1193031/v1

License: (c) (i) This work is licensed under a Creative Commons Attribution 4.0 International License.

Read Full License 

biodiversity and ecosystem services using bat faeces Andrew P. Harrington ${ }^{1}, \wedge^{\wedge}$ Allan D. McDevitt ${ }^{2}$, and ${ }^{\wedge}$ Denise B. O’Meara ${ }^{1}$ of Salford, Salford, UK.

3: National Museum of Ireland - Natural History, Merrion Square West, Dublin 2, Co. Dublin, Ireland.

* Joint first authors

$\wedge$ Joint last authors

Corresponding authors' email addresses:

thomascurran303@gmail.com (Thomas G. Curran) 
Arthropod populations are constantly changing due to changes in climate and the globalisation of trade and travel. Effective and diverse monitoring techniques are required to understand these changes. DNA metabarcoding has facilitated the development of a broad monitoring method to sample arthropod diversity from environmental and faecal samples. In this study, we applied DNA metabarcoding to DNA extracted from bat faecal pellets of Rhinolophus hipposideros, the lesser horseshoe bat in Ireland, a highly protected bat species of conservation concern in Europe. From as few as 24 bat faecal pellets, we detected 161 arthropod species, spanning 11 orders, including 38 pest species of which five were determined to be priority pests, highlighting important ecosystem services. We also report the identification 14 species not previously reported in Ireland, but upon further investigation found that many of these are likely misidentified due to inadequacies in the genetic reference database. For the first time, we were able to use non-invasively collected bat samples to examine the role of sex in the diet of bats and found that the male and female diets did not differ significantly. However, sampling location did explain variation within the diet, highlighting how landscape features influence arthropod composition and diversity. We discuss the current limitations of the methodology in Ireland, how these can be overcome in future studies, and how this data can be used for biodiversity monitoring and informing conservation management of protected bat species. 
Biodiversity plays a globally important role in the successful functioning of healthy ecosystems, vital for human health, wellbeing and food production, collectively known as ecosystem services (Díaz et al. 2019; Dainese et al. 2019). Declines in biodiversity are associated with habitat loss caused by agricultural intensification, urbanisation, globalisation of trade and climate change (Hallmann et al. 2017). Reduced biodiversity can lead to weakened ecosystem resilience, resulting in the loss of economically important species such as pollinators, while promoting the establishment and subsequent spread of invasive species, pests, and disease vectors, through the simplification of landscapes and the creation of favourable habitats to enable their establishment (Clare 2014; Isbell et al. 2018; Dainese et al. 2019; Browett et al. 2020).

Projections of the Paris Agreement on Climate Change show that up to $40 \%$ of global insect diversity is in decline and at risk of extinction, and despite some uncertainty regarding the magnitude of this crisis, scientists collectively agree that a decline is occurring (Warren et al. 2018; Komonen et al. 2019; Sanchez-Bayo and Wyckhuks 2019, Thomas et al. 2019). Of ten major taxonomic orders, $37 \%$ of species are in decline, and $18 \%$ of mainly agricultural and nuisance pest species, are increasing in population numbers (Sanchez-Bayo and Wyckhuks (2021). Butterfly populations in the United Kingdom (UK) and the Netherlands have declined by around 50\% between 1976 and 1990 (Warren et al. 2021). Some of the biggest challenges surrounding biodiversity and vector/ pest monitoring is the labour-intensive work that is required for sampling, morphological identification, and the counting of individual species. This work is vital for the generation of robust surveillance data but requires intensive field sampling and taxonomic expertise making large-scale longitudinal surveys expensive and difficult (Pataki et al. 2021). Traditional approaches inadequately account for the importance of trophic interactions between species within a habitat, hindering the effectiveness of subsequent management strategies. Indirect monitoring of biodiversity via environmental sources or the diet of a predator, such as insectivorous bat species, can provide data regarding the composition and 
interactions of species within a community (de Sousa et al. 2019), providing a more holistic approach to assessment.

Bats are described as indicators of diversity and can be studied relatively easily across landscapes using well-established surveillance methods (Jones et al. 2009; Park 2015; Russo and Jones 2015; Russo et al. 2018; Harrington et al. 2019). Bats are considered specialised hunters, with different species seeking areas of open, narrow and edge space habitats to hunt (Denzinger and Schnitzler 2013; Heim et al. 2016). In Europe, Pipistrellus spp. and Nyctalus spp. forage over open arable and pasture landscapes, but more variable habitat mosaics containing trees promote activity of species such as Myotis, Plecotus, and Rhinolophus spp., offering a broader suite of ecosystem services, vital for the overall functioning of healthy ecosystems (Heim et al. 2015). Bats can also suppress crop pests and potential vectors of disease relevant to human and animal health (Maine and Boyles 2015; Ancillotto et al. 2017; Taylor et al. 2018; Baroja et al. 2019).

Traditional dietary analysis of faecal samples involves hard-part analysis, a labour-intensive process which is limited by time constraints, an inability to detect soft-bodied prey and low taxonomic resolution (Clare 2014; Tournayre et al. 2020), thus reducing the ability to carry out informative studies across broad geographical areas. The advent of Next Generation Sequencing (NGS) technology has revolutionised our capability to gain greater dietary resolution and insights from faecal material (Deagle et al. 2019; de Sousa et al 2019; Browett et al. 2020). DNA metabarcoding can be described as the simultaneous and parallel identification of multiple taxa using a standardised region of DNA. It is a useful technique not only to address questions related to the diet of a species, but it can also be used as an ecosystem approach to detect and track trophic interactions at spatio-temporal scales (Bohmann et al. 2014) with significant developments in the analysis of mammalian diets being made over the last decade (Pompanon et al. 2012; Shokralla et al. 2014; Tournayre et al. 2020; Browett et al. 2020, 2021; Tournayre et al. 2021). 
Across Europe, several studies have applied DNA metabarcoding to bat faeces to understand bat trophic niches and the insect communities that they predate upon (Arrizabalaga-Escudero et al. 2019; Galan et al. 2018; Swift et al. 2018). DNA metabarcoding of the lesser horseshoe bat (Rhinolophus hipposideros) diet within a vineyard-dominated Mediterranean agroecosystem showed that the species is a natural suppressor of many insect pests that negatively impact agriculture (Baroja et al. 2019) and consumption of pest species by $R$. hipposideros was higher than for other bat species (Baroja et al. 2021). Such evidence can support the establishment of management programmes favouring population growth of bats, thereby benefiting insect diversity and the wider agricultural community via the suppression of pest species.

An investigation into the diet of the greater horseshoe bat ( $R$. ferrumequinum) in France found that the core diet consisted of a small number ( $n=15$ common prey species) of preferred taxa ( $25 \%$ of all occurrences), and a secondary diet (75\%) consisted of rare prey that varied between sampling occasions and colonies. Demonstrating that high dietary plasticity might enable adaptation to changing environments and habitats (Tournayre et al. 2021). A degree of functional flexibility was also evident within the trophic niche of $R$. euryale, as it consumed a wide range Lepidoptera which varied in their energy content throughout the season (Arrizabalaga-Escudero et al. 2019).

Browett et al. (2021) optimised a dual primer approach for the DNA metabarcoding of bat diet using DNA previously extracted from non-invasively collected faeces, previously identified to species, sex and individual level using real-time PCR and microsatellite genotyping (Harrington 2018; Harrington et al. 2019). This approach uses proven good quality and quantity DNA, and excludes low quality samples, and facilitates the inclusion of questions related to sex and individual level dietary preferences. Such questions were previously only addressed in studies that captured bats and placed them in cloth bags to facilitate the collection of faeces (Mata et al. 2016; Galan et al. 2017; Arrizabalaga-Escudero et al. 2019), but species such as $R$. hipposideros are sensitive to disturbance 
113 (Weinberger et al. 2009) and best studied using a non-invasive approach (Harrington 2018; Baroja et 114 al. 2021).

115 Rhinolophus hipposideros is the only horseshoe bat species that occurs in Ireland, and has a restricted 116 range, occurring in parts of six counties along the western coast (Fig. 1), with the next closest 117 population occurring in Wales, Britain. resulting in its isolation from all other European populations 118 (Carden et al. 2010; Roche et al. 2015; Dool et al. 2016; Harrington 2018). The most recent Article 17 119 conservation and population assessment (required under the European Habitats Directive) reported 120 that the species is increasing in range, but numbers are declining (NPWS 2019), and genetic studies 121 have shown that populations are becoming increasingly fragmented and isolated, a risk for future 122 extinction (Dool et al. 2016; Harrington 2018).

123 Building on the work of Browett et al. (2021), the aim of this study is to further explore the diet of $R$. 124 hipposideros to describe the overall arthropod diversity present within the species' diet and demonstrate the ecosystem services provided through the identification of insect pest species that can negatively impact agriculture and those implicated in the spread of disease. For the first time, we were also able to investigate differences in diet between sexes and populations using non-invasively collected samples. Based on our findings, we make recommendations on how the technology can be used to its full potential as a tool for assessing and surveying arthropod biodiversity across spatiotemporal scales. 
132 The methodology surrounding the collection and processing of the $R$. hipposideros samples $(n=24)$ used in this study was fully described in Harrington (2018) and Browett et al. (2021). Briefly, the faecal pellets of $R$. hipposideros were non-invasively collected by Harrington (2018) at six roosts within the distribution of the species in the west of Ireland (Fig. 1) under license from NPWS (licence number DER/BAT 2016-29). Each DNA extract was identified to species and sex using real-time PCR assays (Harrington 2018; Harrington et al. 2019) and identified to individual level using a panel of seven microsatellite markers originally designed by Puechmaille et al. (2005) and re-designed and optimised by Harrington (2018). Twenty-four R. hipposideros samples were used as part of this DNA metabarcoding work and evenly represented sex ( $n=12$ for male and female samples) and location ( $n=4$ samples from each of the six roosts with sex evenly represented at each roost).

DNA was amplified using the primers designed by Zeale et al. (2011) and Gillet et al. (2015) that targeted 157 bp and 133 bp fragments of the Cytochrome C Oxidase Subunit 1 (COI) gene, respectively. Using a combination of COI primers aids in maximising amplification and assessment of diversity within the diet. Extended details regarding PCR reaction mixes, multiplexing, thermocycling conditions, library preparation, sequencing, and bioinformatic steps required to generate Molecular Operational Taxonomic Units (MOTUs) are provided in Browett et al. (2021).

Taxonomic Assignment

Taxonomic assignment was made by assigning MOTUs generated to species level with a minimum identity of $98 \%$ requiring at least $90 \%$ coverage using the GenBank and BOLD databases, the latter of which was used to confirm identification when MOTUs presented more than one possible specieslevel identification and were removed from the dataset when more than one species was assigned to the same MOTU (Supplementary Information 1,2,3). If multiple MOTUs were assigned to the same species, they were agglomerated together using the sum of their sequence reads. 
Using the R packages ggplot2, tidyverse, and knitR a "donut chart" was constructed to graphically present taxonomic data for each MOTU detected within the $R$. hipposideros diet (donut chart script source at https://github.com/ShrewlockHolmes/Taxa_Donut_Chart_Visual). The donut chart was separated into three levels, each representing a different taxonomic rank i.e. order, family and genus. The outermost level also contained a number providing an indication of the number of species within that genus that was identified.

Associations between dietary composition at the levels of sex and location were assessed using multiple statistical measures. The data were transformed into relative read abundance (RRA) using the transform_sample_counts function within the R package phyloseq to provide an indication of how common or rare certain taxa are in relation to other taxonomic groups. Stacked bar plots were constructed in the R package ggplot2 using the RRA for each order.

Using RRA, a distance matrix was created using the Bray-Curtis dissimilarity method. Permutational multivariate analysis of variance (PERMANOVA) was performed using the adonis2 function in the $\mathrm{R}$ package vegan (Oksanen et al., 2019) with 10,000 permutations to determine compositional difference in the prey taxa identified within the R. hipposideros diet by sex and location. To ensure that the homogeneity of variance within the groups was not affecting the compositional differences, the function betadisper() was used to measure the multivariate distance of samples to the group centroid. All diversity measures described here were repeated with MOTUs agglomerated to order, family, genus, and species taxonomic ranks. The data were then visualised using a non-metric multidimensional scaling (NMDS) ordination plot $(R$ scripts available at: https://github.com/ShrewlockHolmes/Browett and Curran et al 2021 Mam Biol). Analysis of similarities (ANOSIM), a non-parametric measure, was used to determine differences between two or more groups (i.e. six locations and two sexes) compared to the mean of ranked dissimilarity within groups (Clarke and Green 1988; Chiarucci et al. 2019). This was performed in R using function anosim 
in the package vegan with 9,999 permutations to calculate the difference between the dietary dataset

181 for a given factor, i.e. sex and location $(R$ scripts available at:

182 https://jkzorz.github.io/2019/06/11/ANOSIM-test.html). The ANOSIM provides two measures, statistic $\mathrm{R}$ and significance. The statistic $\mathrm{R}$ is a measure that compares the mean of ranked dissimilarities between groups to the mean of ranked dissimilarities within groups. Statistic $R$ values indicate similarities and differences within and between groups. Values close to zero indicate an even distribution, and no difference between groups. Positive values suggest that similarity is occurring more within groups instead of between groups (McCoy 2020; Chiarucci et al. 2019). Values less than 0.05 are considered statistically significant.

To explore the potential ecosystem services provided by $R$. hipposideros in Ireland, the dietary species identified were compared to previously published works by Baroja et al. (2019) and Tournayre et al. (2021) as both studies identified agriculturally important pest species occurring in the Mediterranean and Continental European diets of $R$. hipposideros and $R$. ferrumequinum. The species identified were also compared to the Arthemis database (http://arthemisdb.supagro.inra.fr), which contains a repository of 2,185 known arthropod pest species in France (Tournayre et al. 2021). The Arthemis database contains information about the host plant range that the arthropods affect. Using the plot_heatmap function in the R package phyloseq and ggplot2, a heatmap indicating the abundance of pest species that were identified as posing potential agricultural and economic burden within the R. hipposideros diet was constructed.

The overall list of identified species from this study was compared to records of arthropod diversity documented within Ireland using several established record repositories including Biodiversity Ireland https://biodiversityireland.ie/, Moths Ireland http://www.mothsireland.com/, the Irish Biogeographical Society, and the Natural History collections of the National Museum of Ireland. 


\section{Dietary composition}

205

206

207

A total of $8,967,124$ sequence reads were obtained from the MiSeq sequencing run, as outlined in Browett et al. (2021). A threshold of $98 \%$ for sequence clustering was applied for downstream analysis. This threshold has been applied in several studies involving the use of the COI genetic region for invertebrate identification (e.g. Alberdi et al. 2018; Browett et al. 2021). This threshold, coupled with robust species-level confirmation using GenBank and BOLD databases, amounted to the generation of 348 MOTUs (164 MOTUs identified using primers designed by Gillet et al. [2015], and 184 MOTUs identified using primers designed by Zeale et al. [2011]) from 24 R. hipposideros faecal pellets (Supplementary Information 1,2, and 3).

These 348 MOTUs represented ten arthropod orders (Araneae, Coleoptera, Diptera, Glomerida, Hemiptera, Hymenoptera, Isopoda, Lepidoptera, Neuroptera, and Trichoptera), and one Annelida order (Opisthopora: Crassiclitellata); consisting of 60 families, 120 genera, and 161 species (Fig. 2). The most dominant order in the diet was Lepidoptera, followed by Diptera (Table 1), which accounted for $55.23 \%$ and $18.01 \%$ of species in the diet, respectively. The orders Araneae, Hymeoptera, and Trichoptera occurred less frequently in the diet and accounted for six, seven, and fifteen of the identified species respectively ( $17.4 \%$ of the overall species level diet) (Table 1$)$. Species identified within rarely occurring orders / suborders, such as Coleoptera (1.24\%), Crassiclitellata (1.24\%), and Glomerida (0.62\%) contributed marginally to the overall diet of $R$. hipposideros. Furthermore, several species were recorded in this study that have not previously been documented in Ireland (see discussion and Supplementary Information 4 for further details).

Barplots were constructed based on RRA to represent the variations of $R$. hipposideros diet according to roost site location and sex (Fig. 3). At the roost level, Lepidoptera and Diptera were found to be the most dominant orders overall with the exception of roost 3 (Co. Kerry), where the order Hymenoptera was dominant. When diet was investigated by sex, Lepidoptera and Diptera were again the dominant 
orders. Female $R$. hipposideros tended to consume more Lepidoptera than males. Less frequently occurring orders including Neuroptera, Trichoptera and Hymenoptera were also more common in the female diet, with Trichoptera only occurring in the female diet and Neuroptera and Hymenoptera rarely occurring in males.

The PERMANOVA showed that sex did not have a statistically significant effect on the diet of $R$. hipposideros $\left(\mathrm{R}^{2}:\right.$ 0.00273-0.0236, $\operatorname{Pr}(>\mathrm{F})$ : $\left.>0.05\right)$. However, roost location was found to be a statistically significant factor impacting the $R$. hipposideros diet $\left(R^{2}: 0.26115-0.3276, \operatorname{Pr}(>\mathrm{F}):<0.01\right)$ (Table 2). The $\mathrm{R}^{2}$ values showed that between $26 \%$ and $32 \%$ of distance variation (depending on the taxonomic rank assessed) was caused by the roost location. This data, at each taxonomic rank, was also visualised using NMDS plots (Fig. 4). The NMDS plots showed that at order level there was an overlap in most of the roost locations, with slight variation. However, roost 3 (Co. Kerry) formed its own cluster outside of the other locations. This pattern can be seen at all taxonomic ranks, where some overlap of each roost was observed, with slight variation, except for roost 3 , showing that the diet of $R$. hipposideros at this roost differed to the others.

The Permutest and Tukey analysis showed that sample homogeneity did not influence the compositional difference detected via PERMANOVA as all $p$-values at both sex and roost for all taxonomic ranks were $>0.05$.

The ANOSIM results also corroborated the trend observed via PERMONVA as sex differences were not found to influence dietary composition. Statistic $\mathrm{R}$ values for sex ranged from $-2.11 \times 10^{-2}$ to $1.61 \times 10^{-}$ ${ }^{2}$, and significance at all taxonomic ranks was $>0.05$ showing that sex did not significantly impact diet. However, roost location was again found to have a statistically significant effect on the diet of $R$. hipposideros, with statistic $\mathrm{R}$ ranging from 0.19 to 0.40 , and significance values for all taxonomic ranks $<0.01$. 
253 A total of 38 potential pest species were identified, representing almost $24 \%$ of the overall species

254 identified in the diet (Table 3). Pest species were mostly Lepidopteran species, with 35 of the 38 255 ( 92\%) pest species identified as Lepidoptera. The rest of the potential pest species identified 256 consisted of two Diptera species ( 5\%) and one Hemiptera species ( 2\%) (Supplementary Information $2575)$.

258 Of the 38 species listed in Table 3, five species were identified as posing a significantly negative environmental impact. These were two Lepidoptera species: Archips podanus and Plutella xylostella, two Diptera species: Tipula oleracea and Chamaepsila rosae, and one Hemiptera species Drepanosiphum platanoidis. A heatmap of the read abundance of these five species within each of the R. hipposideros samples included in this study ( $\mathrm{n}=24)$ was constructed (Fig. 5). From the heatmap, Tipula oleracea was the most commonly occurring pest species across each of the bat samples,

264 followed by Plutella xylostella. Chaempsila rosae, Drepanosiphum platanoidis and Archips podanus were only found to occur within the diet of one $R$. hipposideros individual each. 
In this study, we expanded upon our earlier work (Browett et al. 2021) where we developed a dual primer DNA metabarcoding approach to study the diet of insectivorous mammals. Here, we further explored the diet of a bat species, $R$. hipposideros, and described the range of arthropods found in its diet, with a particular focus on the effects of roost location and sex and explored the ecosystem services provided by the species in the form of pest species consumption. This and the earlier work by Browett et al. (2021) are the first studies in Ireland or Great Britain to use a DNA metabarcoding approach to examine the diet of $R$. hipposideros. McAney and Fairley (1989) used traditional hard-part analysis to identify the remains of insects predated upon by $R$. hipposideros and reported eight arthropod orders occurring within the diet from 630 faecal pellets, but here, DNA metabarcoding allowed for the detection of 11 orders from as few as 24 faecal pellets. Of the 11 orders detected here, three are not typical constituents of bat diet (i.e. Annelida order [Opisthopora: Crassiclitellata], Glomerida, and Isopoda). It is likely that these detections are a result of exposure to environmental contamination during sample collection rather than actual dietary constituents (Aldasaro et al. 2019; Browett et al. 2021). In McAney and Fairley (1989), arthropods were only identified to family level, whereas here we have been able to identify arthropod species predated upon by $R$. hipposideros, something not normally achievable via hard-part analysis. This highlights the sensitivity of the DNA metabarcoding approach over traditional hard-part methods and the resolution of the data generated.

\section{Location- and Sex-based Dietary Variation}

Roost location was found to be the most informative variable to explain dietary differences across the dataset, which was also found to be the case in $R$. ferrumequinum when studied in France (Tournayre et al. 2021). Here, the diet of $R$. hipposideros was dominated by Diptera and Lepidoptera, but their frequencies and composition varied according to location. The order Hymenoptera was relatively abundant at roost 3 (Co. Kerry) and was also detected at roost 1 (Co. Mayo), but at a lower abundance. 
Some less frequently occurring orders were also identified, including Araneae, Coleoptera, Crassiclitellata, Neuroptera, and Trichoptera. Araneae, Coleoptera, and Trichoptera were all identified in Co. Kerry. Dietary variation, particularly for the Kerry site, was evident in Fig. 4, where the points around the group centroid for the Kerry samples clustered separately to the other five locations. Even though the other roosts are located near woodland areas, most are in agriculture-dominated areas, whereas the Kerry site is located in the centre of a heavily wooded area, considered as ideal habitat for R. hipposideros in Ireland. The site in Co. Kerry is of international interest as it is a Special Area of Conservation (SAC) for a range of priority habitats listed on Annex I and II of the European Habitats Directive. This suggests that $R$. hipposideros diet is representative of what arthropods are present at the time of sampling (i.e. opportunistic foraging) and that variable habitats play a role in influencing bat diet. This is a factor which should be considered for future studies intending to use DNA metabarcoding as a tool to investigate arthropod diversity and presence/absence of target organisms/groups (Thomsen and Willerslev 2015).

Our analysis showed that the sex of the bat did not significantly impact their diet, with both male and female $R$. hipposideros having a heavy Dipteran and Lepidopteran based diet, but again at varying frequencies, but were not statistically significant. Females appeared to prefer Lepidoptera over Diptera, while males predated more often on Diptera (Fig. 3). The female diet was also found to include less frequently occurring orders (i.e. Hymenoptera, Neuroptera, and Trichoptera). Similar observations have been made in other studies, such as a hard part analysis study of the wrinkle-lipped free-tailed bat (Tadarida plicata), where females predated on more Lepidoptera and Coleoptera and fewer Odonatathan than males (Leelapaibul et al. 2005), and a DNA metabarcoding study showed that female European free-tailed bat (Tadarida teniotis) predated upon larger and more migratory species than males (Mata et al. 2016). Female bats have high energy requirements during breeding, pregnancy, and lactation (Racey and Entwistle 2000), which may influence their hunting strategies to focus on larger prey items with a higher energy content to support their nutritional demands. These subtle but important differences could be further investigated using the molecular approach outlined 
in this study combined with an increased sample size to provide more statistically robust insights into sex-biased dietary preferences.

\section{Ecosystem Services}

A total of 38 potential pest species were detected in this study, but the magnitude of the risk posed by each of these species in Ireland is not well known, as the species were identified by comparing the data generated from this study with studies from Spain and France (Baroja et al. 2019; Tournayre et al. 2021) and the Arthemis Database based in France. However, some of the more well recognised pest species that we explored using the heatmap (Fig. 5) showed how the diet of the bat can be used to detect and monitor the distribution of pest species, in addition to providing a natural method for pest removal. Five known agricultural pests identified were further investigated due to their recognised economic, societal, and environmental impacts.

The most infrequently occurring pest items included Chamaepsila rosae (Diptera: Psilidae); Drepanosiphum platanoidis (Hemiptera: Aphididae) and Archips podanus (Lepidoptera: Tortricidae) each detected in one individual with a total of six reads for the former two species and 12 reads in the later. Chamaepsila rosae or carrot fly primarily affects crops such as carrots and parsnips (Collier et al. 2020) and has been described as a major carrot pest within Europe (Szwejda and Wrzodak 2007). Drepanosiphum platanoidis, an aphid, is a significant pest of ornamental and amenity trees belonging to the genus Acer, particularly, sycamore trees, and can excrete an abundance of honeydew, providing ideal conditions for the growth of moulds such as Cryptostroma corticale causing "sooty bark disease", resulting in tree mortality (Parry et al. 1989; Binggeli and Rushton 1999; Morecroft et al. 2008). Archips podanus, the fruit tree tortrix moth (often referred to as $A$. podana) is polyphagous and is considered to be an important pest of fruit trees including apple, plum, and cherry and reduces the quality of the fruit harvested (Hrudová 2003; Stará and Kocourek 2004). Studies have found that the abundance of this species is not influenced by insecticide use, highlighting the value of bat predation for the suppression of this species (Cross 1996; Stará and Kocourek 2004). 
The most frequently occurring pest species included Plutella xylostella (Lepidoptera: Plutellidae) and Tipula oleracea (Diptera: Tipulidae) detected in detected in four and nine individuals with a total of 47 and 102,224 sequence reads respectively. Considered to be a global and economically important pest species, the Diamondback moth, $P$. xylostella is known to be destructive to brassicaceous crops worldwide (Talekar and Shelton 1993; Zalucki et al. 2012; Li et al. 2016). Control strategies for managing this insect pest are met with difficulty as studies have shown a degree of insecticide resistance by this pest species (Talekar and Shelton 1993; Zalucki et al. 2012; Furlong et al. 2013; Xia et al. 2018). The common crane fly (T. oleracea) is found throughout Ireland and Europe (cabi.org 2019; Peck et al. 2006; 2008) and is commonly referred to as an agricultural and horticultural pest of winter cereals, brassicas, clover, strawberries, turnips and several other vegetables and ornamentals (Blackshaw and Coll 1999; Peck et al. 2006; 2008).

\section{Biodiversity}

The dataset generated here suggested the presence of 14 arthropod species not previously reported in Ireland (Figure S4). However, further investigation revealed uncertainties that these identifications were truly new, and more likely caused by an inadequate reference database. A little over $10.5 \%$ of the species level identifications generated from this study provided inconclusive results, despite using internationally accepted thresholds for identification (Alberdi et al. 2018; Alberdi et al. 2020; Browett et al. 2021).

A number of species, unlikely to be present in Ireland, were identified in this study. Oricia truncata identified with $98.7 \%$ sequence identity across 223 sequence reads occurs exclusively in Central America (Miller 2009). The next closest species level identification acquired from the MOTU generated for this species was for Prays rucifeps and Homorthodes naverca, both of which had a lower sequence similarity of $97.4 \%$, making it very difficult to suggest an identification for this MOTU. Tholera americana, a native species to North America and not present in Ireland was identified in this study (98.7\%) from two individuals with sequence reads ranging from 26 to 67 . However, it is likely that we 
have identified one of two other Tholera species documented in Ireland, T. cespitis and T. decimalis (both listed as critically endangered on Moths Ireland) (Bond and O'Connor 2012), but not present on the genetic reference database. Tholera cespitis and $T$. decimalis have a limited and localised distribution, found in parts of the west of Ireland such as the Burren in Co. Clare and parts of west Cork, Kerry, and Galway (Bond and Gittings 2008), overlapping with sampling locations used for this study, suggesting that it is likely that one of those species were identified. Further DNA barcoding and the generation of a morphologically identified reference database would be an invaluable resource to enable more accurate identifications.

Five cranefly species were identified as potential new species records for Ireland in this study, Tipula banffiana (99.4\% identity [1096 sequence reads across eight individuals]), Tipula coleana (98.5\% identity [six sequence reads from one individual]), Tipula luridorostris ( $99.2 \%$ identity [353 sequence reads across five individuals]), Tipula platymera (99.2\% identity [108 sequence reads across six individuals]) and Metalimnobia triocellata (98.1\% [371 reads from one individual]). Previous bat dietary studies have reported a number of Tipula spp. predated upon and this arthropod group appears to be a common feature within the diet (Andriollo et al. 2019). Other Tipula species identified in this study and previously recorded in Ireland include $T$. oleracea and $T$. varipennis. Craneflies are well documented in Ireland via the "Craneflies of Ireland" database, but the vast majority of the species have not been DNA barcoded, and we cannot accurately identify the sequences to species level without the generation of an accurate genetic reference database. Similar identification difficulties were experienced in relation to Mesochorus suomiensis, a parasitoid wasp in the family Ichneumonidae. The MOTU for this species was identified with $98.8 \%$ similarity and was recorded in two individuals with sequence reads ranging from eight to 601 , but this particular genus of hyperparasitoids and other ichneumonids have been described as being poorly understood in respect to taxonomy (O'Connor et al. (2007). 
The application of DNA metabarcoding here has also allowed for the detection of potential vector organisms that have been implicated in the spread of disease. In this study, several mosquito (Diptera: Culicidae) and midge (Diptera: Ceratopogonidae) species were identified including Culex pipiens, $C x$. quinquefasciatus, Culiseta annulata, Cs. morsitans, and Culicoides impunctatus. The mosquito species Cx. quinquefasciatus has not previously been reported in Ireland or Great Britain. Across the British Isles, five Culex species have been documented, only one of which has been recorded in Ireland, $C X$. pipiens (Ashe et al. 1991; Folly et al. 2020). Here, Cx. quinquefasciatus was detected in two individuals with 328 sequence reads and implies that Irish mosquito species are potentially underestimated and Culex species may be more diverse than previously thought. The potential occurrence of this species in Ireland poses a risk for future arthropod-borne disease outbreaks e.g. West Nile Virus and highlights the need for effective and multidisciplinary surveillance methods of vector organisms. However, the sequence region used in this study was very short and often much longer and additional gene regions, such as the second internal transcribed spacer (ITS2) of the ribosomal RNA, are required for accurate species identification and differentiation of the Culex complex (e.g. Laurito et al. 2013). In addition, care has to be taken that the originally deposited sequence was also accurately identified. However, the approach of using a predator diet to indirectly survey potential airborne vectors has shown great promise in this study and has the potential to be a powerful surveillance tool.

Additionally, this study adds further records of two Lepidoptera species (Bactra lacteana and Prays ruficeps) which were recently observed in Ireland (Bond et al. 2017; Bond 2018). Five Bactra spp. have been recorded, B. furfurana (also recorded in this study), B. lancealana, B. robustana, and B. vanosana (a migrant species). Bactra lacteana and B. lancealana are said to be highly morphologically similar species. But, in this case $B$. lacteana was identified within the diet of four $R$. hipposideros, with a total of 5725 sequence reads, with $100 \%$ sequence similarity and $100 \%$ sequence query cover and the species is well represented on the GenBank database. However, no reference DNA barcode exists for B. lancealana. Prays rucifeps, a micromoth, was detected in one individual with 10,685 sequence reads and with $100 \%$ identity. The species was first recorded in Ireland in 2000 (Moths Ireland) but was not 
reported in Bond and O'Connor (2012), and only two recordings for P. rucifeps exist, both of which have been in the east of Ireland. However, a closely related species P. faxinella is present in Ireland and $P$. rucifeps was formerly considered to be a dark variant of this species, but DNA barcoding has enabled the distinction between these two species. When the MOTU generated in this study was compared to $P$. faxinella it was found to only be $97 \%$ similar, providing good confidence that both $P$. rucifeps and P. faxinella are present in Ireland as has been recognised in Britain (Barnett 2017), and that it is more common and widespread than previously thought.

\section{Conclusion}

In this study, DNA metabarcoding of relatively few bat faecal pellets provided a large arthropod dataset. We found that the location of the bat roost was an important factor to explain dietary variation in $R$. hipposideros, a finding which could be adapted in future studies aiming to investigate the impact of land use on biodiversity. Our findings were not limited by the methodology we employed, but by the lack of available DNA sequences present on reference databases to compare Irish insect diversity. Our study was relatively small in scale but as a result, we were in a position to robustly critique our identifications and are consequently provide recommendations to further expand this work to better use the technology for future applications which include monitoring of biodiversity, bat diet, ecosystem services and even as early warning systems for the tracking of pests and vectors. Future studies could include the development of a reference arthropod library using malaise traps, morphological identification, and DNA barcoding to generate more robust datasets for biodiversity recording (e.g. deWaard et al. 2019). In addition, DNA barcoding of target species such as those collected by Moths Ireland and those submitted to the National Museum of Ireland and Biodiversity Ireland could be DNA barcoded to generate genetic references or DNA barcodes for morphologically identified species. Indeed, our findings have similar and relevant implications for other geographically remote and isolated regions. Our work has shown that $R$. hipposideros provides 
442 to suppress with the use of insecticidal methods, which are also known to be detrimental to wider

443 insect diversity. Our work suggests that promoting and conserving bats and their associated habitats,

444 particularly in areas of crop production, would benefit food producers, bat conservation and insect

445 diversity. 
447 Alberdi A, Aizpurua O, Gilbert MTP, Bohmann K (2018) Scrutinizing key steps for reliable metabarcoding of environmental samples. Methods Ecol Evol 9(1):134-147.

Alberdi A, Razgour O, Aizpurua O, Novella-Fernandez R, Aihartza J, Budinski I, Garin I, Ibáñez C, Izagirre

E, Rebelo H, Russo D, Vlaschenko A, Zhelyazkova V, Zrnčić V, Gilbert TP (2020) DNA metabarcoding and spatial modelling link diet diversification with distribution homogeneity in European bats. Nature Communications 11:1154. https://10.1038/s41467-020-14961-2

454

455

456

457

458

459

460

461

462

463

464

465

466

467

468

469

Ancillotto L, Ariano A, Nardone V, Budinski I, Rydell J, Russo D (2017) Effects of free-ranging cattle and landscape complexity on bat foraging: Implications for bat conservation and livestock management. Agriculture, Ecosystems and Environment 241:54-61. https://doi.org/10.1016/i.agee.2017.03.001

Andriollo T, Gillet F, Michaux JR, Ruedi M (2019) The menu varies with metabarcoding practices: A case study with the bat Plecotus auritus. PLoS ONE 14(7):e0219135. https://doi.org/10.1371/journal.pone.0219135

Arrizabalaga-Escudero A, Clare EL, Salsamendi E, Alberdi A, Garrin I, Aihartza J, Goiti U (2018) Assessing niche partitioning of co-occurring sibling bat species by DNA metabarcoding. Molecular Ecology 27(5):1273-1283. https://doi.org/10.1111/mec.14508

Arrizabalaga-Escudero A, Merckx T, García-Baquero G, Wahlberg N, Aizpurua O, Garin I, Goiti U, Aihartza J (2019) Trait-based functional dietary analysis provides a better insight into the foraging ecology of bats. Journal of Animal Ecology 88(10):1587-1600. https://doi.org/10.1111/1365$\underline{2656.13055}$

Ashe P, O'Connor J, Casey R (1991) Irish Mosquitoes (Diptera: Culicidae): A Checklist of the Species and Their Known Distribution. Proceedings of the Royal Irish Academy. Section B: Biological, Geological and Chemical Science. 91B, 21-36. 
Baroja U, Garin I, Aihartza J, Arrizabalaha-Escudero A, Vallejo N, Aldasoro M, Goiti U (2019) Pest 14(7):e0219265

Baroja U, Garin I, Vallejo N, Aihartza J, Rebelo H, Goiti U (2021) Bats actively track and prey on grape pest populations. Ecological Indicators 126:107718. https://doi.org/10.1016/j.ecolind.2021.107718

Binggeli P, Rushton BS (1999) Sycamore and Ash: A review of aspects relevant to Irish forestry. COFORD, Dublin

Blackshaw RP, Coll C (1999) Economically important leatherjackets of grassland and cereals: biology, https://doi.org/10.1023/a:1009625724013

Bond, KGM (2018) Additions and amendments to the Irish microlepidoptera list since 2011.

Entomologists' Record and Journal of Variation, 130, 113-120

Bond KGM, Gittings T (2008) Database of Irish Lepidoptera. 1 - Macrohabitats, microsites and traits of Noctuidae and butterflies. Irish Wildlife Manuals, No. 35. National Parks and Wildlife Service, Department of the Environment, Heritage and Local Government, Dublin, Ireland. 
Browett SS, O'Meara DB, McDevitt AD (2020) Genetic tools in the management of invasive mammals: recent trends and future perspectives. Mamm Rev 50(2):200-210. https://doi.org/10.1111/mam.12189

Carden R, Aughney T, Kelleher C, Roche N (2010) Irish bat monitoring schemes: BATLAS Republic of

500 Ireland report for 2008-2009. Bat Conservation Ireland. Available from:

https://www.batconservationireland.org/wp-

Chiarucci A, Nascimbene J, Campetella G, Chelli S, Dainese M, Giorgini D, Landi S, Lelli C, Canullo R (2019) Exploring patterns of beta-diversity to test the consistency of biogeographical boundaries: A case study across forest plant communities of Italy. Ecology and Ecolution 9(20):11716-11723.

Clare EL (2014) Molecular detection of trophic interactions: emerging trends, distinct advantages, significant considerations and conservation applications. Evolutionary Applications 7(9):1144-1157. https://doi.org/10.3390/insects11060369 orchards in England subject to different insecticide management. Entomologist, 115: 168-180 
Dainese M, Martin EA, Aizen MA, Albrecht M, et al. (2019) A global synthesis reveals biodiversitymediated benefits for crop production. Science Advances 5(10): eaax0121.

de Sousa LL, Silva SM, Xavier R (2019) DNA metabarcoding in diet studies: Unveiling ecological aspects

DNA 1(3): 199-214. Counting with DNA in metabarcoding studies: how should we convert sequence reads to dietary data? Mol Ecol 28(2):391-406. https://doi.org/10.1111/mec.14734

Denzinger A, Schnitzler H-U (2013). Batguilds, a concept to classify the highly diverse foraging and echolocation behaviours of microchiropteran bats. Front Physiol 4:164.

527 Díaz S, Settele J, Brondízio ES et al. (2019) Pervasive human-driven decline of life on Earth points to

528 the need for transformative change. Science 366(6471): eaax3100.

Dool SE, Peuchmaille SJ, Kelleher C, McAney K, Teeling EC (2016) The effect of human-mediated habitat fragmentation on a sedentary woodland species (Rhinolophus hipposideros) at its range margin. Acta Chiropterologica 18(2):377-393. https://doi.org/10.3161/15081109ACC2016.18.2.006

Folly AJ, Dorey-Robinson D,_Hernández-Triana LM, Phipps P Johnson N (2020) Emerging threats to

534 animals in the United Kingdom by arthropod-borne diseases. Frontiers in Veterinary Science 7(20).

536 Furlong MJ, Wright DJ, Dosdall LM (2013) Diamondback moth ecology and management: Problems,

537 Progress, and Prospects. Annual Review of Entomology 58:517-541. https://doi.org/10.1146/annurev- 
539 Galan M, Pons J-B, Tournayre O, Pierre É, Leuchtmann M, Pontier D, Charbonnel N (2018)

540 Metabarcoding for the parallel identification of several hundred predators and their prey: Application

541 to bat species diet analysis. Molecular Ecology Resources 18(3):474-489.

542 https://doi.org/10.1111/1755-0998.12749

543 Gillet F, Tiouchichine M-L, Galan M, Blanc F, Némoz M, Aulagnier S, Michaux JR (2015) A new method

544 to identify the endangered Pyrenean desman (Galemys pyrenaicus) and to study its diet, using next

545 generation sequencing from faeces. Mamm Biol 80(6):505-509.

546 https://doi.org/10.1016/j.mambio.2015.08.002

547 Hallmann CA, Sorg M, Jongejans E, Siepel H, Hofland N, Schwan H, Stenmans W, Müller A, Sumser H, 548 Hörren T, Goulson D, de Kroon H (2017). More than 75 percent decline over 27 years in total flying 549 insect biomass in protected areas. PLoS ONE 12(10): e0185809.

551 Harrington AP (2018) The development of non-invasive genetic methods for bats of the British Isles.

552 Unpublished PhD thesis, Waterford Institute of Technology

553 Harrington AP, O'Meara DB, Aughney T, McAney K, Schofield H, Collins A, Deenen H, O'Reilly C (2019)

554 Novel real-time PCR species identification assays for British and Irish bats and their application to a

555 non-invasive survey of bat roosts in Ireland. Mamm Biol 99:109-118.

556 https://doi.org/10.1016/j.mambio.2019.10.005

557 Heim O, Schröder A, Eccard J, Jung KG, Voigt CC (2016). Seasonal activity patterns of European bats

558 above intensively used farmland. Agriculture, Ecosystems and Environment 233:130-139.

559 https://doi.org/10.1016/j.agee.2016.09.002

560 Heim O, Treitler JT, Tschapka M, Knörnschild M, Jung K (2015). The importance of landscape elements

561 for bat activity and species richness in agricultural areas. Plos One 10(7):e0134443. 
Hrudová E (2003) The presence of non-target Lepidopteran species in pheromone traps for fruit

564 tortricid

moths.

Plant

Protect.

Sci.

39(4):126-131.

https://www.agriculturejournals.cz/publicFiles/51593.pdf

566

Isbell F, Cowles J, Dee LE, Loreau M, Reich PB, Gonzalez A, Hector A, Schmid B (2018) Quantifying

effects of biodiversity on ecosystem functioning across times and places. Ecol Lett 21(6):763-778.

https://doi.org/10.1111/ele.12928

569

Jones G, Jacobs DS, Kunz TH, Racey PA (2009) Carpe noctem: the importance of bats as bioindicators.

570

Endangered Species Research 8(1): 93-115. https://doi.org/10.3354/esr00182

Komonen A, Halme P, Kotiaho JS (2019) Alarmist by bad design: Strongly popularized unsubstantiated

572

claims undermine credibility of conservation science. Rethinking Ecology 4:17-19.

573

https://doi.org/10.3897/rethinkingecology.4.34440

574

Laurito M, Oliveira TM, Almirón WR, Sallum MA (2013). COI barcode versus morphological identification of Culex (Culex) (Diptera: Culicidae) species: a case study using samples from Argentina and Brazil. Mem Inst Oswaldo Cruz. 2013;108 Suppl 1(Suppl 1):110-122. doi:10.1590/00740276130457

Leelapaibul W, Bumrungsri S, Pattanawiboon A (2005) Diet of wrinkle-lipped free-tailed bat (Tadarida plicata Buchannan, 1800) in central Thailand: insectivorous bats potentially act as biological pest control agents. Acta Chiropterologica 7(1):111-119. https://doi.org/10.3161/17335329(2005)7[111:DOWFBT]2.0.CO;2

582 Li Z, Feng X, Liu SS, You M, Furlong MJ (2016) Biology, ecology, and management of the Diamondback moth in China. Annual Review of Entomology 61:277-96. https://doi.org/10.1146/annurev-ento- 

large migratory moths in the European free-tailed bat (Tadarida teniotis). Biology Letters 12(3): e20150988. https://doi.org/10.1098/rsbl.2015.0988

McCoy (2020) Beta-Diversity Analysis "ANOSIM": R packageMedlock JM, Hansford KM, Schaffner F, Versteirt V, Hendrickx G, Zeller H, Van Bortel W (2012) A review of the invasive mosquitoes in Europe: ecology, public health risks, and control options. Vector-Borne and Zoonotic Diseases 12(6):435-447. https://doi.org/10.1089/vbz.2011.0814

Miller JS (2009) Generic revision of the Dioptinae (Lepidoptera, Noctuoidea, Notodontidae) Part 1:

Dioptini. Bulletin of the American Museum of Natural History 321:1-674.

Morecroft MD, Stokes VJ, Taylor ME, Morison JIL (2008) Effects of climate and management history on the distribution and growth of sycamore (Acer pseudoplatanus L.) in a southern British woodland in comparison to native competitors. Forestry 81(1):59-74. https://doi.org/10.1093/forestry/cpm045 NPWS (2019). The Status of EU Protected Habitats and Species in Ireland. Volume 3: Species Assessments. Unpublished NPWS report. Edited by: Deirdre Lynn and Fionnuala O'Neill package version 2.5-6. 
610 Parry WH, Edwards ID, Jenkins TAR (1989) Chemical control of sycamore aphid, Drepanosiphum

611 platanoidis (Schr.), with organophosphorus and soap insecticides. Crop Protection 8:30-36.

612 https://doi.org/ 10.1016/0261-2194(89)90096-3

613 Peck DC, Hoebeke ER, Klass C (2006) Detection and establishment of the European crane flies Tipula 614 paludosa Meigen and Tipula oleracea L. (Diptera: Tipulidae) in New York: a review of their distribution, 615 invasion history, biology, and recognition. Proceedings of the Entomological Society of Washington 616 108(4):985-994.

617 Peck DC, Olmstead D, Morales A (2008) Application timing and efficacy of alternatives for the 618 insecticidal control of Tipula plaudosa (Diptera: Tipulidae), a new invasive pest of turf in northeastern United States. Pest Management Science 64(10):989-1000. https://doi.org/10.1002/ps.1592

Pompanon F, Deagle BE, Symondson WC, Brown DS, Jarman SN, Taberlet P (2012) Who is eating what:

Diet assessment using next generation sequencing. Mol Ecol 21(8):1931-1950.

623 Peuchmaille S, Mathy G, Petit E (2005) Characterization of 14 polymorphic microsatellite loci for the 624 lesser horseshoe bat, Rhinolophus hipposideros (Rhinolophidae, Chiroptera). Mol Ecol Notes 5:941625 944

Racey PA, Entwistle AC (2000) Life-history and reproductive strategies of bats. Reproductive biology of bats (eds EG Krutzsch, PH Crichton) 363-414. London, UK: Elsevier.

Roche N, Aughney T, Langton S (2015) Lesser horseshoe bat: population trends and status of its roosting resource. Irish Wildlife Manuals no. 85. National Parks and Wildlife Service, Department of 
Russo D, Bosso L, Ancillotto L (2018). Novel perspectives on bat insectivory highlight the value of this ecosystem service in farmland: Research frontiers and management implications. Agriculture, Ecosystems and Environment 266:31-38. https://doi.org/10.1016/j.agee.2018.07.024

Sanchez-Bayo F, Wyckhuys KAG (2019) Worldwide decline of the entomofauna: a review of its drivers. Biological Conservation 232, 8-27. https://doi.org/10.1016/j.biocon.2019.01.020

Sanchez-Bayo F, Wyckhuys KAG (2021) Further evidence for a global decline of the entomofauna. Austral Entomology 60, 9-26. http://doi/epdf/10.1111/aen.12509 barcoding: using next-generation sequencing to enhance and accelerate DNA barcode capture from single specimens. Molecular Ecology Resources 14(5):892-901. https://doi.org/10.1111/1755$\underline{0998.12236}$

Stará J, Kocourek F (2004) Flight pattern of Archips podana (Lep.: Torticidae) based on data from traps.

Plant

Protect.

Sci. 40(3):75-81. https://www.agriculturejournals.cz/publicFiles/16872.pdf metabarcoding: Validation of a non-invasive, next-generation approach to studying bat populations.

650 Evolutionary Applications [Special Issue: Next generation conservation genetics and biodiversity monitoring] 11(7):1120-1138. https://doi.org/10.1111/eva.12644 
655

656

657

658

659

660

661

662

663

664

665

666

667

668

669

670

671

672

673

674

675

676

677

Talekar NS, Shelton AM (1993) Biology, ecology, and management of the Diamondback Moth. Annual Review of Entomology 38:275-301. https://doi.org/10.1146/annurev.en.38.010193.001423

Taylor PJ, Grass I, Alberts AJ, Joubert E, Tscharntke T (2018) Economic value of bat predation servicesa review and new estimates from macadamia orchards. Ecosyst Serv 30:372-381

Thomas CD, Jones TH, Hartley SE (2019) "Insectageddon": a call for more robust data and rigorous analyses. Global Change Biology 25(6):1891-1892. https://doi.org/10.1111/gcb.14608

Thomsen PF, Willerslev E (2015) Environmental DNA - an emerging tool in conservation for monitoring past and present biodiversity. Biological Conservation, 183, 4-18.

Tournayre O, Leuchtmann M, Filippi-Cadaccioni O, Trillat M, Piry S, Pontier D, Charbonnel N, Galan M (2020) In silico and empirical evaluation of twelve metabarcoding primer sets for insectivorous diet analyses. Ecol Evolut 10:6310-6332. https://doi.org/10.1002/ece3.6362

Tournayre O, Leuchtmann M, Galan M, Trillat M, Piry S, Pinaud D, Fillipi-Codaccioni O, Poniter D, Charbonnel N (2021) eDNA metabarcoding reveals a core and secondary diets of the greater horseshoe bat with strong spatio-temporal plasticity. Environmental DNA [Special Issue: The future of biodiversity monitoring and conservation utilizing environmental DNA] 3(1):277-296. https://doi.org/10.1002/edn3.167

Warren R, Price J, Graham E, Forstenhaeusler N, VanDerWal J (2018). The projected effects on insects, vertebrates, and plants of limiting global warming to $1.5^{\circ} \mathrm{C}$ rather than $2^{\circ} \mathrm{C}$. Science $360(6390): 791-$ 795. https://doi.org/10.1126/science.aar3646

Warren MS, Maes D, van Swaay CAM, Goffart P, Van Dyke H, Bourn NAD, Wynhoff I, Hoare D, Ellis S (2021) The decline of butterflies in Europe: Problems, significance, and possible solutions. Proceedings of the National Academy of Sciences of the United States of America. 118(2), e2002551117. https://doi.org/10.1073/pnas.2002551117 
678 Weinberger IC, Bontadina F, Arlettaz R (2009) Translocation as a conservation tool to supplement relict 679 bat colonies: a pioneer study with endangered horseshoe bats. ESR 8:41-48. 680 https://doi.org/10.3354/esr00196

681 Xia X, Sun B, Gurr GM, Vasseur L, Xue M, You M (2018) Gut microbiota mediate insecticide resistance 682 in the Diamondback Moth, Plutella xylostella (L.). Front. Microbiol. 9(25): 683 https://doi.org/10.3389/fmicb.2018.00025

684 Zalucki MP, Shabbir A, Silva R, Adamson D, Liu SS, Furlong MJ (2012) Estimating the economic cost of 685 one of the world's major insect pests, Plutella xylostella (Lepidoptera: Plutellidae): Just how long is a 686 piece of string? Journal of Economic Entomology 105(4):1115-1129.https://doi.org/10.1603/EC12107 687 Zeale MRK, Butlin RK, Barker GLA, Lees DC, Jones G (2011) Taxon-specific PCR for DNA barcoding 688 arthropod prey in bat faeces. Mol Ecol Resour 11(2):236-244. https://doi.org/10.1111/i.1755$689 \quad \underline{0998.2010 .02920 . x}$ 
TGC was supported by a Waterford Institute of Technology and Environmental Protection Agency (EPA) cofund PhD Scholarship, funded under the EPA Research Programme 2014-2020. The EPA Research Programme is a Government of Ireland initiative funded by the Department of the Environment, Climate and Communications. It is administered by the EPA, which has the statutory function of co-ordinating and promoting environmental research. SSB was supported by a Pathway to Excellence PhD Scholarship from the University of Salford. Laboratory work was supported by grants from Bat Conservation Ireland $(\mathrm{BCl})$ and a University of Salford Internal Research Award awarded to DBO'M and ADM, and a University of Salford Pump Priming award to ADM. Thanks to the local National Park and Wildlife Service (NPWS) conservation rangers for facilitating APH to sample and collect bat droppings. APH's PhD was supported by grants from the NPWS, BCl and the Vincent Wildlife Trust.

Competing Interests

The authors have no competing interests to declare.

\section{Author Contributions}

706

707

708

\section{Data Availability}

ADM, TGC, SSB, and DBO'M conceived and designed the study. Bat faecal sampling was part of APH, D'ON, DBO'M and CORs project on non-invasive genetic monitoring of lesser horseshoe bats. TGC and SSB performed the laboratory work and bioinformatics associated with the DNA metabarcoding. TGC and $\mathrm{DBO}^{\prime} \mathrm{M}$ analysed the data, AO'H helped with entomological identifications. TGC and DBO'M wrote the paper, with all authors contributing to editing, discussions, and approval of the final manuscript.

The dataset generated and analysed in this study is available in the Supplementary Information. 


\section{Compliance with Ethical Standards}

714 Rhinolophus hipposideros faecal pellets were non-invasively collected by APH at six roosts within the

715 distribution of the species in the west of Ireland under license from NPWS (licence number DER/BAT

$716 \quad 2016-29)$ 
718 Figure 1: Distribution of (A) R. hipposideros in Ireland [MO: Co. Mayo, GY: Co. Galway, CE: Co. Clare,

719 KY: Co. Kerry, LK: Co. Limerick, CO: Co. Cork) and (B) the roosts sampled for R. hipposideros faecal

720 samples for this study.

721 Figure 2: Donut chart representing the orders (inner circle), families (middle circle), and genera (outer circle) of the identified arthropods in the $R$. hipposideros diet. The numbers in the outer circle refer to the number of species identified within that genus.

724 Figure 3: Stacked bar plots showing the relative abundance (\%) of all orders detected in the diet of $R$.

725 hipposideros across the six roosts sampled (1: Co. Mayo, 2: Co. Limerick, 3: Co. Kerry, 4: Co. Cork, 5:

726 Co. Galway, 6: Co. Clare) and sex (female and male) [Black lines represent the relative read abundance for each MOTU within the respective order].

Figure 4: NMDS plots of samples according to the variable location when MOTUs are agglomerated to order, family, genus, and species (Roost $1=$ Co. Mayo, Location $2=$ Co. Limerick, Location $3=$ Co. Kerry, Location 4 = Co. Cork, Location $5=$ Co. Galway, Location $6=$ Co. Clare $)$. diet that are known to be significant pests to the agriculture sector (ID in the sample legend refers to the individual bat sample). 

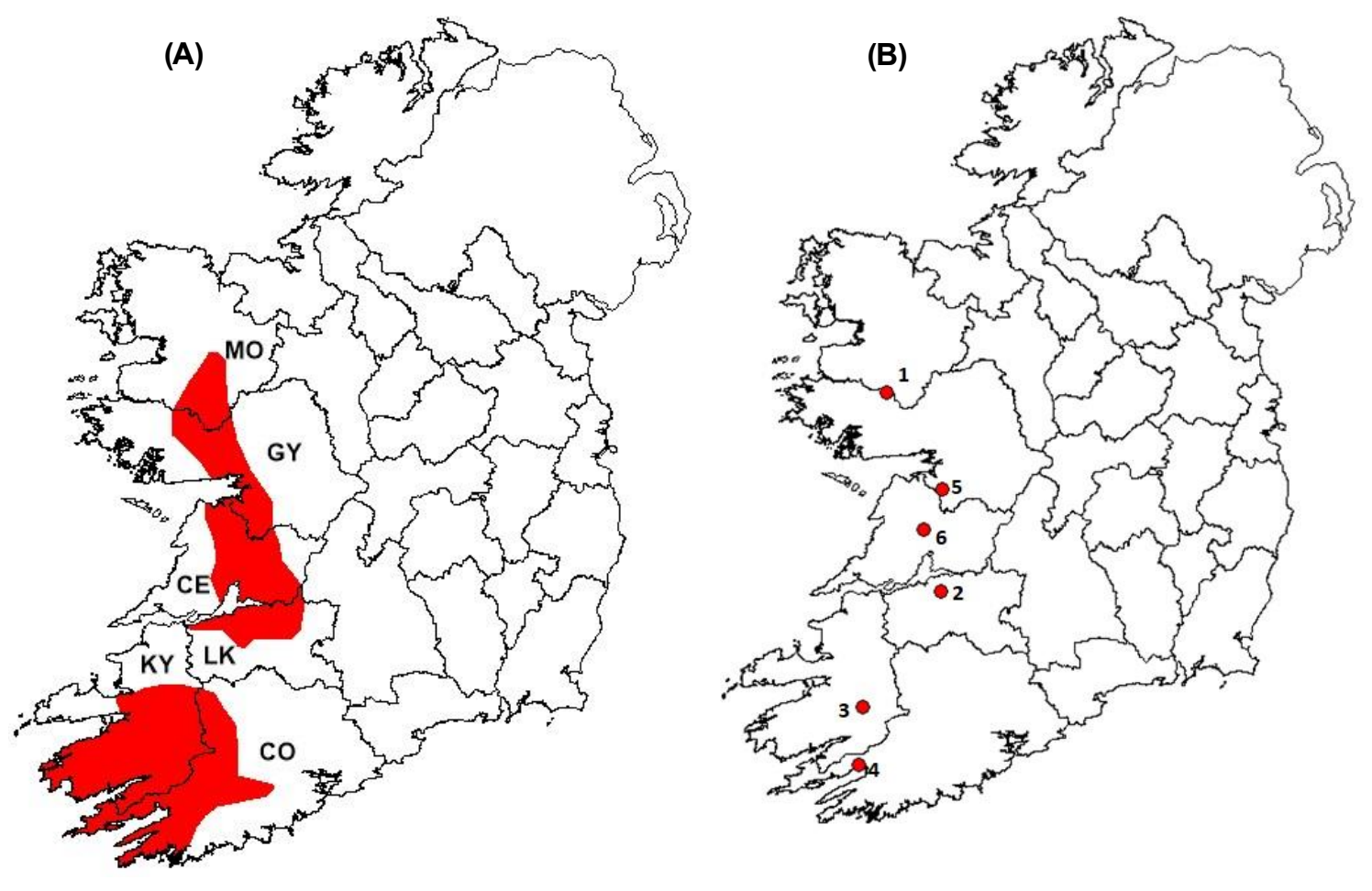


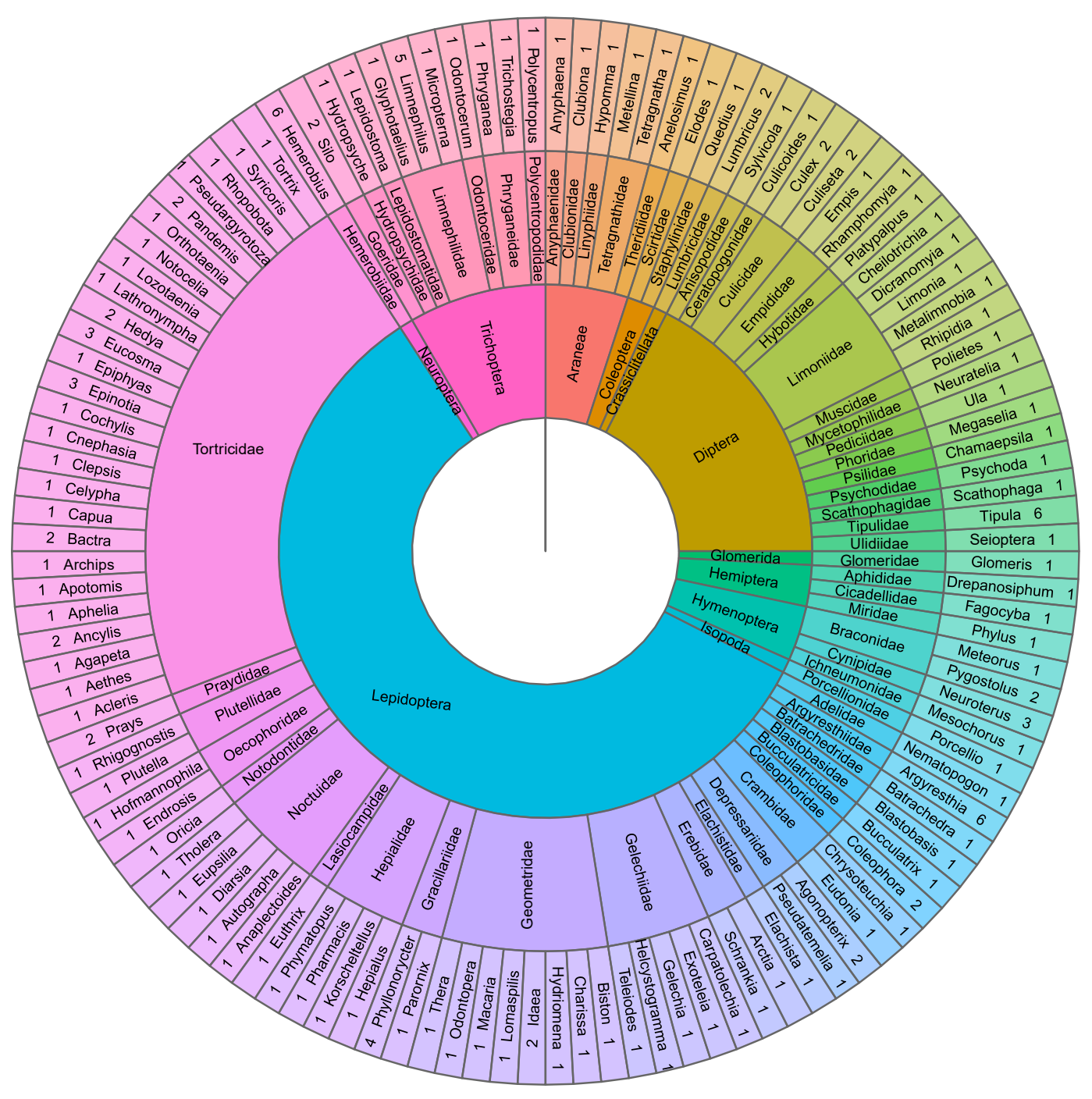



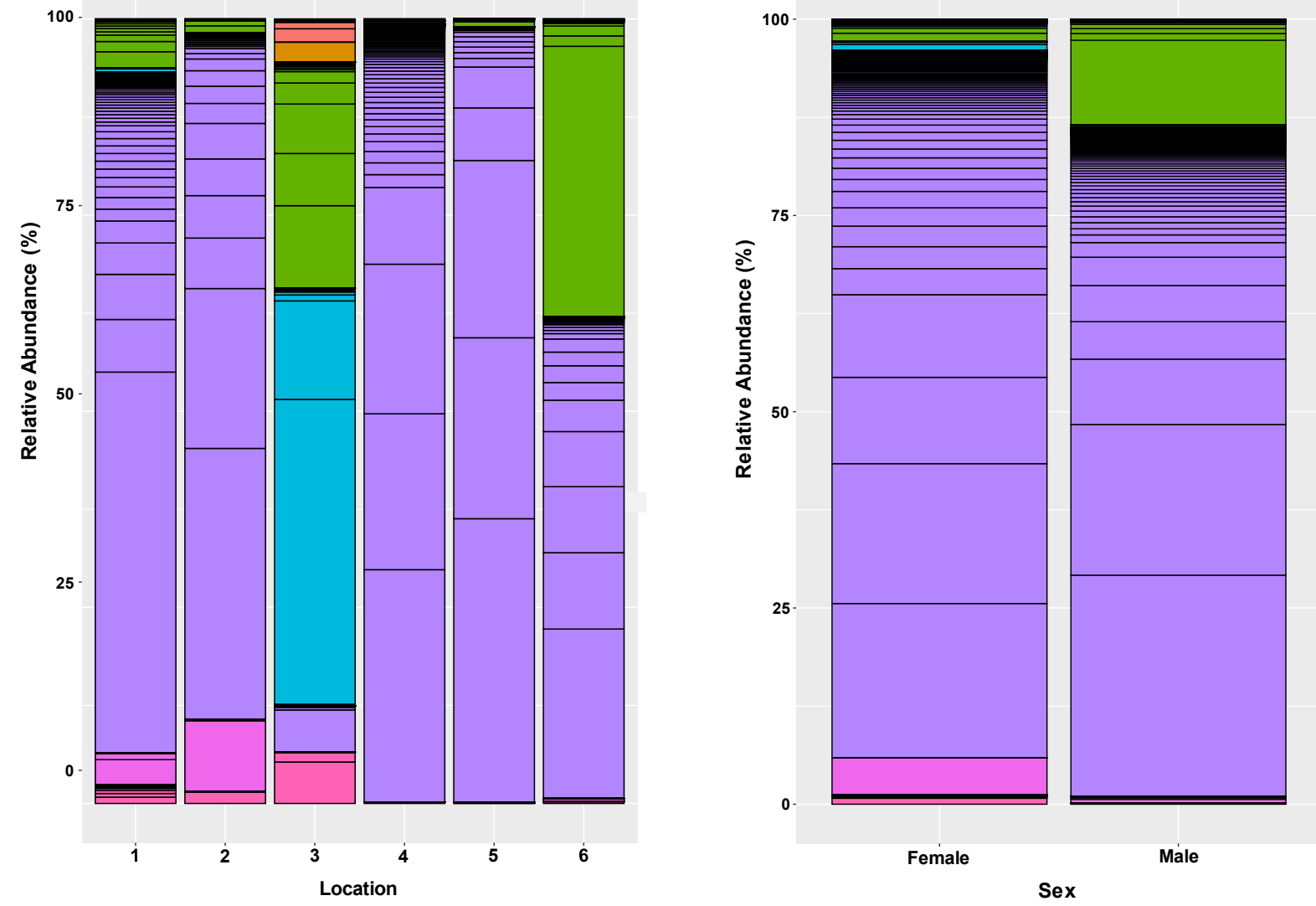

Order $\square$ Araneae $\square$ Coleoptera $\square$ Crassiclitellata $\square$ Diptera $\square$ Glomerida $\square$ Hemiptera

$\square$ Hymenoptera $\square$ Isopoda $\square$ Lepidoptera $\square$ Neuroptera $\square$ Trichoptera 

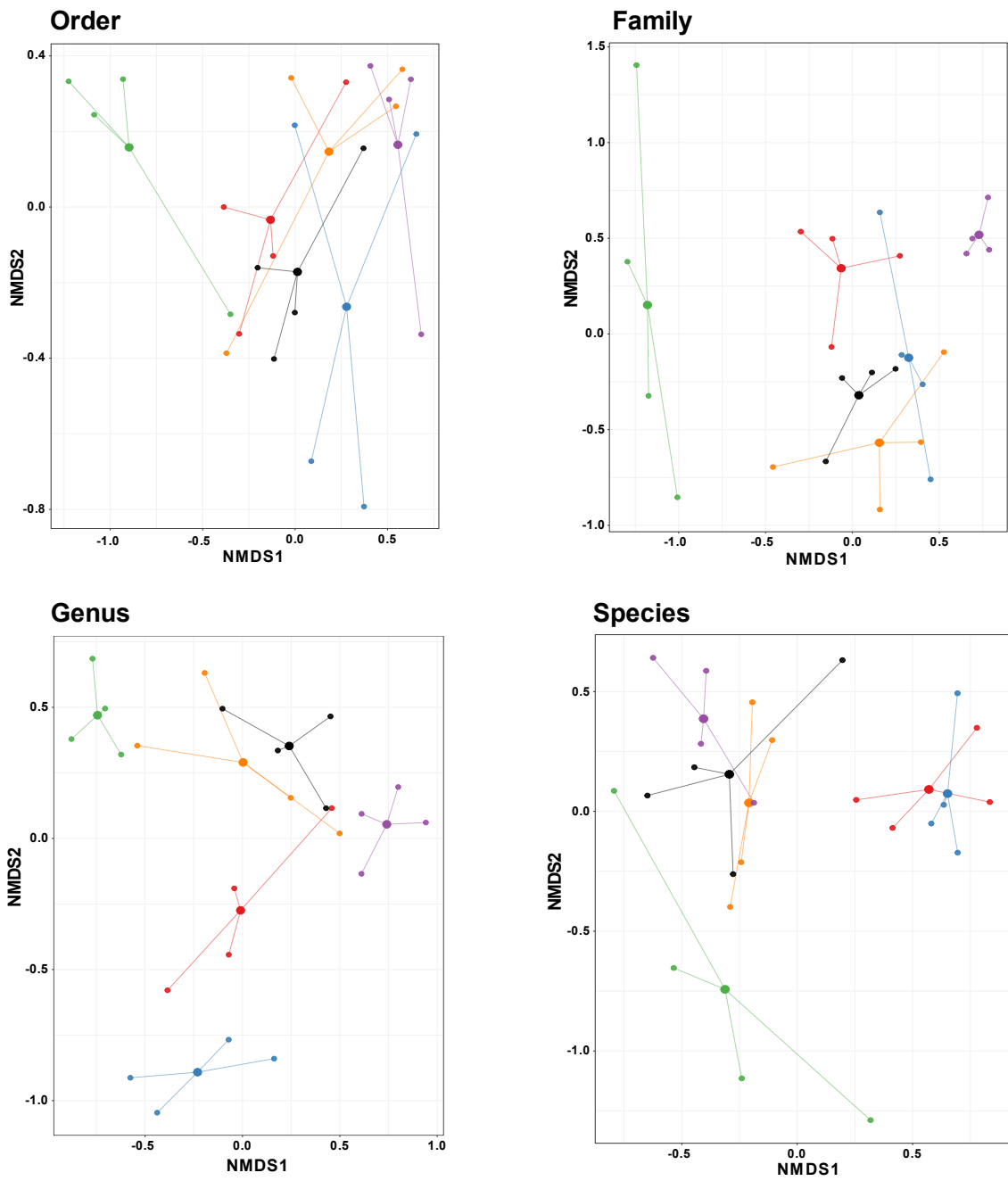

\begin{tabular}{l|l|l|l|l|l} 
& 1 & 2 & &
\end{tabular} 


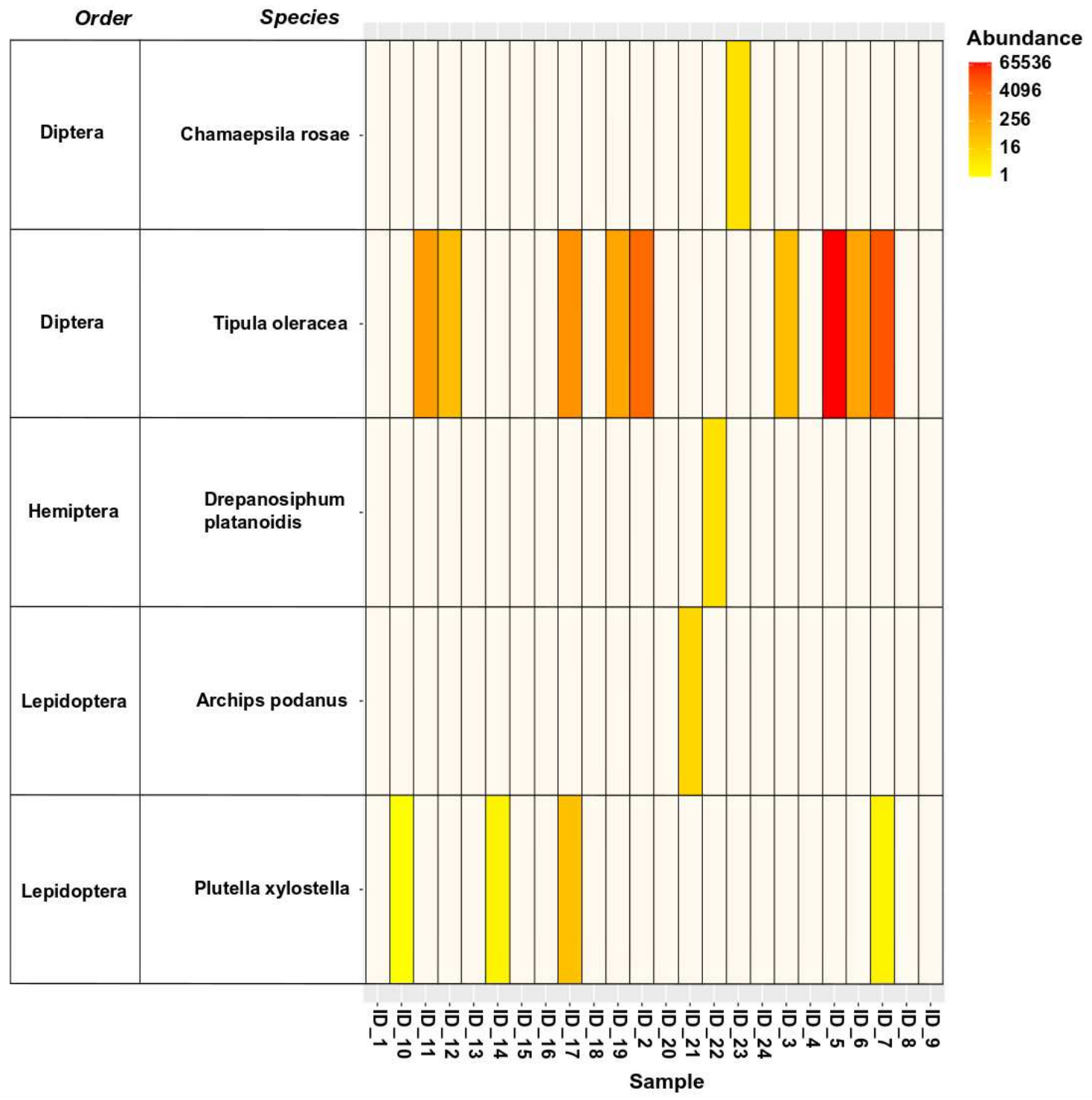

740

741 
Table 1: The numbers of families, genera, and species identified within each order (via GenBank and BOLD) that contributed to the overall diet of $R$. hipposideros.

\begin{tabular}{cccc}
\hline Order & Families & Genera & Species \\
\hline Lepidoptera & 21 & 70 & 90 \\
Diptera & 15 & 21 & 28 \\
Trichoptera & 7 & 10 & 15 \\
Hymenoptera & 3 & 4 & 7 \\
Araneae & 5 & 6 & 6 \\
Neuroptera & 1 & 1 & 6 \\
Hemiptera & 3 & 3 & 3 \\
Coleoptera & 2 & 2 & 2 \\
Crassiclitellata & 1 & 1 & 2 \\
Glomerida & 1 & 1 & 1 \\
Isopoda & 1 & 1 & 1 \\
\hline Total & $\mathbf{6 0}$ & $\mathbf{1 2 0}$ & $\mathbf{1 6 1}$ \\
\hline
\end{tabular}

747

Table 2: Statistical analyses (PERMANOVA, ANOVA, PERMUTEST and ANOSIM) performed on the $R$. roost and sex on the diet.

\begin{tabular}{|c|c|c|c|c|c|c|}
\hline & \multicolumn{6}{|c|}{ Sex } \\
\hline & \multicolumn{2}{|c|}{ PERMANOVA } & \multirow{2}{*}{$\begin{array}{c}\text { ANOVA } \\
\operatorname{Pr}(>\mathrm{F})\end{array}$} & \multirow{2}{*}{$\begin{array}{c}\text { PERMUTEST } \\
\operatorname{Pr}(>\mathrm{F})\end{array}$} & \multicolumn{2}{|c|}{ ANOSIM } \\
\hline & $\mathbf{R}^{2}$ & $\operatorname{Pr}(>\mathrm{F})$ & & & Statistic R & Significance \\
\hline Order & $2.73 \times 10^{-3}$ & 0.97 & 0.97 & 0.96 & $-2.11 \times 10^{-2}$ & 0.83 \\
\hline Family & $1.92 \times 10^{-2}$ & 0.62 & 0.82 & 0.81 & $1.61 \times 10^{-2}$ & 0.27 \\
\hline Genus & $2.26 \times 10^{-2}$ & 0.47 & 0.65 & 0.64 & $1.61 \times 10^{-2}$ & 0.27 \\
\hline \multirow[t]{4}{*}{ Species } & $2.36 \times 10^{-2}$ & 0.39 & 0.62 & 0.61 & $1.61 \times 10^{-2}$ & 0.27 \\
\hline & \multicolumn{6}{|c|}{ Roost Location } \\
\hline & \multicolumn{2}{|c|}{ PERMANOVA } & ANOVA & PERMUTEST & \multicolumn{2}{|c|}{ ANOSIM } \\
\hline & $R^{2}$ & $\operatorname{Pr}(>\mathrm{F})$ & $\operatorname{Pr}(>F)$ & $\operatorname{Pr}(>F)$ & Statistic R & Significance \\
\hline Order & $3.30 \times 10^{-1}$ & $2 \times 10^{-4}$ & 0.12 & 0.13 & 0.19 & $2 \times 10^{-4}$ \\
\hline Family & $2.73 \times 10^{-1}$ & $9.999 \times 10^{-5}$ & 0.66 & 0.67 & 0.40 & $1 \times 10^{-4}$ \\
\hline Genus & $2.64 \times 10^{-1}$ & $9.999 \times 10^{-5}$ & 0.94 & 0.93 & 0.40 & $1 \times 10^{-4}$ \\
\hline Species & $2.61 \times 10^{-1}$ & $9.999 \times 10^{-5}$ & 0.91 & 0.92 & 0.40 & $1 \times 10^{-4}$ \\
\hline
\end{tabular}


Table 3: List of 38 potential pest species identified in the diet of $R$. hipposideros in the west of Ireland via comparison to Baroja et al. (2019) $\left[{ }^{1}\right]$, Tournayre et al. (2021) [ $\left.{ }^{2}\right]$, and the Arthemis database $\left[{ }^{3}\right]$. database.

\begin{tabular}{|c|c|c|}
\hline Order & Species & Host Plant Range \\
\hline Lepidoptera & Acleris schalleriana $^{1}$ & $\begin{array}{l}\text { Populus tremula, Viburnum lantana, Viburnum } \\
\text { opulus }\end{array}$ \\
\hline Lepidoptera & Agonopterix conterminella ${ }^{3}$ & Salix \\
\hline Lepidoptera & Agonopterix nervosa ${ }^{3}$ & $\begin{array}{l}\text { Anthriscus cerefolium, Apium graveolens, Daucus } \\
\text { carota sativus, Pastinaca sativa, Pimpinella } \\
\text { anisum }\end{array}$ \\
\hline Lepidoptera & Archips podanus (A. podana) ${ }^{3}$ & $\begin{array}{l}\text { Abies, Alnus, Betula, Citrus, Clematis, Cornus mas, } \\
\text { Corylus, Crataegus, Cydonia oblonga, Euonymus } \\
\text { japonicus, Fagus, Fraxinus, Heracleum, Juglans, } \\
\text { Lonicera, Malus, Picea, Populus, Primula, Prunus, } \\
\text { Prunus cerasus, Prunus domestica, Prunus } \\
\text { persica, Pyrus communis, Rhododendron, Ribes, } \\
\text { Rosa, Salix, Sorbus, Tilia, Trifolium, Vaccinium } \\
\text { myrtillus, Vitis vinifera }\end{array}$ \\
\hline Lepidoptera & Arctia villica ${ }^{3}$ & $\begin{array}{l}\text { Achillea, Centaurea, Cynara scolymus, Erysimum } \\
\text { cheiri (hyb.), Fragaria, Lamium, Plantago, Rubus, } \\
\text { Taraxacum, Urtica, Vitis vinifera }\end{array}$ \\
\hline Lepidoptera & Argyresthia conjugella ${ }^{3}$ & $\begin{array}{l}\text { Crataegus, Fraxinus, Malus, Prunus padus, } \\
\text { Sorbus, Sorbus aucuparia }\end{array}$ \\
\hline Lepidoptera & Argyresthia laevigatella ${ }^{3}$ & Larix, Larix decidua, Larix kaempferi \\
\hline
\end{tabular}

Lepidoptera Argyresthia spinosella ${ }^{1}$

Lepidoptera Celypha lacunana

Diptera

Lepidoptera Lepidoptera

Lepidoptera Cnephasia incertana ${ }^{1}$

Hemiptera Drepanosiphum platanoidis ${ }^{3}$

Lepidoptera Epinotia tedella ${ }^{3}$ Lepidoptera Epinotia tenerana ${ }^{2}$ Lepidoptera Eupsilia transversa ${ }^{3}$ Lepidoptera Exoteleia dodecella ${ }^{1}$
Host Plant Range

Populus tremula, Viburnum lantana, Viburnum opulus

Anthriscus cerefolium, Apium graveolens, Daucus carota sativus, Pastinaca sativa, Pimpinella anisum

Corylus, Crataegus, Cydonia oblonga, Euonymus japonicus, Fagus, Fraxinus, Heracleum, Juglans, Prunus cerasus, Prunus domestica, Prunus persica, Pyrus communis, Rhododendron, Ribes, , Trifolium, Vaccinium Achillea, Centaurea, Cynara scolymus, Erysimum cheiri (hyb.), Fragaria, Lamium, Plantago, Rubus, Taraxacum, Urtica, Vitis vinifera

Sorbus, Sorbus aucuparia Larix, Larix decidua, Larix kaempferi

Fragaria, Larix, Ligustrum, Mentha, Myosotis, Picea, Primula, Quercus, Ranunculus, Rubus, Salix, Agrimonia, Anthriscus cerefolium, Betula, Caltha palustris, Chrysanthemum, Cirsium, Spiraea, Ulmus, Urtica, Viola

Apium graveolens, Carum carvi, Daucus carota sativus, Pastinaca sativa, Petroselinum crispum Agrostis, Dactylis

Arundo donax, Centaurea, Cyclamen, Euphorbia, Iris, Lilium, Rosa, Rumex acetosa, Spiraea, Urtica, Viola, Vitis vinifera

Aster, Centaurea, Chrysanthemum, Cirsium, Dianthus, Fragaria, Lotus, Medicago, Primula, Saxifraga,

Vicia faba, Vitis vinifera

Acer campestre, Acer monspessulanum, Acer platanoides, Acer pseudoplatanus

Picea

Alnus, Betula, Corylus

Populus 
Lepidoptera Hedya nubiferana ${ }^{1 / 2}$

Lepidoptera Hedya pruniana ${ }^{1 / 2}$

Lepidoptera Hepialus humuli ${ }^{2}$

Lepidoptera Hydriomena furcata

Lepidoptera Lomaspilis marginata ${ }^{2}$

Lepidoptera Lozotaenia forsterana ${ }^{2}$

Lepidoptera Notocelia trimaculana ${ }^{3}$

Lepidoptera Odontopera bidentata ${ }^{3}$

Lepidoptera Orthotaenia undulana ${ }^{1 / 2}$

Lepidoptera Pandemis cerasana ${ }^{2}$

Lepidoptera Pandemis heparana ${ }^{2}$

Lepidoptera Parornix devoniella ${ }^{1}$

Lepidoptera Phyllonorycter maestingella ${ }^{3}$

Lepidoptera Phyllonorycter quercifoliella ${ }^{3}$

Lepidoptera Phyllonorycter salicicolella ${ }^{3}$

Lepidoptera Plutella xylostella ${ }^{1 / 2}$

Lepidoptera Prays fraxinella ${ }^{2}$
Alnus, Betula, Crataegus, Fraxinus, Fraxinus excelsior, Malus, Prunus, Prunus armeniaca, Prunus cerasus, Prunus domestica, Prunus dulcis, Prunus persica, Pyrus communis, Quercus, Ribes uva-crispa, Rosa, Salix, Sorbus

Crataegus, Malus, Prunus, Prunus cerasus, Prunus domestica, Pyrus communis, Salix, Sorbus

Anemone, Asparagus, Asparagus officinalis, Aster, Beta vulgaris, Brassica napus var. napobrassica, Brassica rapa, Campanula, Cannabis sativa, Chrysanthemum, Convallaria majalis, Cynara scolymus, Dahlia, Daucus carota sativus, Delphinium, Fragaria, Fungi, Gladiolus, Helianthus tuberosus, Humulus lupulus, Iris, Lactuca sativa, Lupinus, Narcissus, Paeonia, Pastinaca, Phaseolus, Phlox, Pisum sativum, Rumex, Solanum tuberosum, Taraxacum

Abies balsamea, Corylus avellana, Picea sitchensis, Populus, Salix, Salix caprea

Betula pendula, Corylus avellana, Populus, Populus nigra, Populus tremula, Salix, Salix aurita, Salix caprea

Campanula, Hedera, Lonicera, Prunus laurocerasus

Crataegus

Abies, Betula, Fagus, Fraxinus excelsior, Larix, Larix decidua, Malus, Picea abies, Pinus sylvestris, Populus alba, Populus nigra betulifolia, Prunus domestica, Quercus, Ribes uva-crispa, Salix, Sorbus aucuparia, Tilia, Tilia platyphyllos, Trifolium pratense, Vaccinium myrtillus

Acer, Alnus, Betula, Hippophae rhamnoides, Juniperus, Lonicera, Pinus, Salix, Ulmus

Acer, Acer pseudoplatanus, Betula, Crataegus, Fraxinus, Prunus, Pyrus communis, Quercus, Rhamnus, Ribes, Rosa, Sorbus, Sorbus aucuparia, Tilia

Betula, Forsythia, Lonicera, Malus, Populus, Prunus, Prunus cerasus, Prunus domestica, Prunus persica, Pyrus communis, Salix, Tilia Corylus

Fagus sylvatica, Wisteria floribunda

Quercus

Salix

Brassica napus, Brassica oleracea, Brassica oleracea var. botrytis, Brassicaceae, Capparis spinosa, Cicer arietinum, Fragaria, Matthiola incana, Papaver, Raphanus, Reseda, Tropaeolum Fraxinus excelsior 
Lepidoptera Rhopobotanaevana ${ }^{3}$

Diptera Tipula oleracea $a^{1 / 2}$

Lepidoptera Tortrix viridana ${ }^{2}$
Crataegus, Ericallex aquifolium, Malus, Prunus domestica, Pyrus communis, Rhamnus, Sorbus, Vaccinium myrtillus

Populus, Quercus, Quercus robur

756 


\section{Supplementary Files}

This is a list of supplementary files associated with this preprint. Click to download.

- Supplementarylnformation.xlsx 